\title{
Diretrizes Ergonômicas para o Teletrabalho em Home-office
}

\section{Ergonomic Guidelines for Home-office Teleworking}

\author{
GODOY, Lígia de; Bacharel; Universidade do Estado de Santa Catarina
}

ligiadegodoy@gmail.com

FERREIRA, Marcelo Gitirana Gomes; Doutor; Universidade do Estado de Santa Catarina

marcelo.gitirana@gmail.com

\section{Resumo}

As transformações sociais, culturais e tecnológicas da nossa sociedade fazem surgir novos paradigmas de trabalho. O teletrabalho, frequentemente realizado no ambiente residencial, é um desses novos paradigmas e vem despertando preocupações em relação à ergonomia. A falta de legislação específica e a escassez de estudos científicos sobre o assunto demonstram a necessidade de pesquisas que analisem a situação desses trabalhadores. O presente estudo buscou levantar as principais normas e recomendações em ergonomia, direcionando-as ao teletrabalho em ambiente residencial, ou home-office. A partir da pesquisa, percebeu-se que é necessário adaptar as normas existentes ao ambiente residencial e à atividade do teletrabalho, além de ser importante a sua divulgação como guia a profissionais e organizações. Isso pode ser feito em estudos futuros, também com o apoio de pesquisas empíricas.

Palavras Chave: teletrabalho; home-office; ergonomia.

\begin{abstract}
The social, cultural and technological transformations of our society give rise to new paradigms of work. Telework, often performed in the residential environment, is one of these new paradigms and has been raising concerns about ergonomics. The lack of specific legislation and the scarcity of scientific studies on the subject demonstrate the need for research that analyzes the situation of these workers. The present study sought to raise the main norms and recommendations in ergonomics, directing them to the telework in residential environment, or home-office. It was noticed that it is necessary to adapt the existing norms to the residential environment and the activity of teleworking, besides being important its dissemination as a guide to professionals and organizations. This can be done in future studies, also with the support of empirical research.
\end{abstract}

Keywords: telework; home-office; ergonomics. 


\section{Introdução}

As transformações sociais, tecnológicas e culturais da nossa sociedade ao longo do tempo acarretaram mudanças nos paradigmas de habitação e trabalho. $O$ surgimento de novos paradigmas de trabalho se fortalece em especial após a década de 1990, motivado tanto pelos avanços tecnológicos como pela democratização de acesso aos computadores pessoais. As mudanças nas formas de trabalho, inevitavelmente, despertam novas preocupações em relação à saúde do trabalhador. Os novos paradigmas de trabalho, em especial o teletrabalho, apresentam novas demandas no que tange aos fatores humanos e à ergonomia. O teletrabalho apresenta especificidades que devem ser consideradas no seu estudo, como a autonomia do trabalhador, a flexibilidade de horários e a variedade de locais onde pode ser desempenhado. Com o profissional trabalhando individualmente, no ambiente da sua própria residência, por exemplo, a adequação dos espaços e ferramentas passa a ser controlada por ele próprio. Tem-se, portanto, uma possível transferência de responsabilidades, que antes cabiam ao empregador, para o trabalhador. A falta de legislação específica que regulamente o teletrabalho, aliada à escassez de publicações científicas que analisem o tema considerando aspectos de diversos âmbitos, demonstram a importância de novos estudos direcionados à situação desses trabalhadores quanto à ergonomia. O presente artigo busca levantar diretrizes, normas e recomendações relacionadas à ergonomia, adaptando-as ao caso específico dos teletrabalhadores em home-office, ou seja, aqueles que desempenham atividades de trabalho no ambiente residencial. São considerados no estudo os trabalhadores que realizam atividades classificadas como intelectuais, tradicionalmente desempenhadas em escritórios, com o auxílio de computadores de mesa ou computadores portáteis (laptops). A compilação e adaptação das diretrizes ergonômicas para teletrabalhadores em home-office e a posterior sintetização desses requisitos, poderão ter utilidade em projetos futuros que busquem estudar, de forma empírica, a situação desses trabalhadores em relação à ergonomia, ou mesmo guiar a implementação de programas de teletrabalho em organizações.

\section{Ergonomia}

O significado etimológico da palavra ergonomia deriva do grego: ergon (trabalho) e nomos (legislação ou normas) e pode ser entendido como "o estudo do trabalho" (KARWOWSKI, 2012, p.3) ou, como define Grandjean "a ciência da configuração de trabalho adaptada ao homem" (GRANDJEAN, 1998, p.7). A definição trazida pela Associação Brasileira de Ergonomia, a ABERGO (2017), e adotada pela Associação Internacional de Ergonomia (IEA - International Ergonomics Association) é a seguinte:

A Ergonomia (ou Fatores Humanos) é uma disciplina científica relacionada ao entendimento das interações entre os seres humanos e outros elementos ou sistemas, e à aplicação de teorias, princípios, dados e métodos a projetos a fim de otimizar o bem estar humano e o desempenho global do sistema. Os ergonomistas contribuem para o planejamento, projeto e a avaliação de tarefas, postos de trabalho, produtos, ambientes e sistemas de modo a torná-los compatíveis com as necessidades, habilidades e limitações das pessoas.

A subdivisão da ergonomia trazida pela Associação Internacional de Ergonomia e sustentada pela ABERGO traz três áreas principais: Ergonomia Física, Ergonomia Cognitiva e Ergonomia Organizacional. A Ergonomia Física, em geral, preocupa-se com características da anatomia humana, antropometria, fisiologia e biomecânica, no que tange à atividade física. A Ergonomia Cognitiva é voltada aos processos mentais, como a percepção, memória, raciocínio e resposta motora, em sua relação com as interações entre os seres humanos e outros elementos de um 
sistema. A Ergonomia Organizacional está voltada à otimização dos sistemas sociotécnicos e ao estudo dos novos paradigmas de trabalho, o que inclui o teletrabalho, englobando no seu estudo as estruturas organizacionais, políticas e de processos (ABERGO, 2017). Segundo Hendrick e Kleiner (2002), a teoria dos sistemas sociotécnicos engloba quatro subsistemas principais: o subsistema tecnológico; o subsistema pessoal; o ambiente externo ou subsistema ambiental e o design do sistema de trabalho ou subsistema estrutura organizacional.

O Brasil conta com algumas normas regulamentadoras que norteiam o projeto e avaliação de postos de trabalho quanto à Ergonomia, sendo as analisadas neste estudo a NR 17 - Ergonomia (MTE, 2007), a NBR ISO/CIE 8995-1 - lluminação em Ambientes de Trabalho (ABNT, 2013), que substituiu a ABNT NBR 5413, e a NBR 10152- Acústica - Níveis de Pressão Sonora em Ambientes Internos e Edificações (ABNT, 2017). As normas mencionadas estão dispostas no Quadro 1, que apresenta também o seu título e objetivos ou escopos.

Quadro 1 - Normas

\begin{tabular}{lll}
\hline Norma & Detalhes & Objetivo/Escopo \\
\hline NR 17 - Ergonomia & $\begin{array}{l}\text { Norma Regulamentadora do } \\
\text { Ministério do Trabalho e Emprego }\end{array}$ & $\begin{array}{l}\text { Estabelecer parâmetros que permitam a } \\
\text { adaptação das condições de trabalho às } \\
\text { características psicofisiológicas dos } \\
\text { trabalhadores, de modo a proporcionar } \\
\end{array}$ \\
& $\begin{array}{l}\text { um máximo de conforto, segurança e } \\
\text { desempenho eficiente. }\end{array}$
\end{tabular}

NBR ISO 8995-1 - lluminação Norma Brasileira da ABNTem Ambientes de Trabalho Associação Brasileira de Normas Técnicas, sendo idêntica, em conteúdo técnico, estrutura e redação, à ISO/CIE 8995-1:2002

NBR 10152 - Acústica - Níveis de Pressão Sonora em Ambientes Internos e Edificações
Norma Brasileira da ABNTAssociação Brasileira de Normas Técnicas

\begin{abstract}
Especificar os requisitos de iluminação para locais de trabalho internos e os requisitos para que as pessoas desempenhem tarefas visuais de maneira eficiente, com conforto e segurança durante todo o período de trabalho.
\end{abstract}

Fixar os níveis de ruído compatíveis com o conforto acústico em ambientes diversos.

Fonte: adaptado de MTE (2007), ABNT (2013) e ABNT (2017)

\section{Teletrabalho em Home-Office}

Entre os novos paradigmas de trabalho que vêm se disseminando, o teletrabalho ganha destaque no mundo inteiro. O teletrabalho pode ser definido como uma forma de trabalho realizada de forma remota ao escritório central ou local de produção, sem que o trabalhador tenha contato direto com os colegas de trabalho, sendo facilitado pelas tecnologias de informação e comunicação (ILO, 2016). O teletrabalho pode ser classificado de acordo com diversas variáveis, sendo o local de trabalho uma delas. Pode ser desempenhado em escritórios, pertencentes à empresa ou não; em espaços temporários equipados com os recursos tecnológicos necessários; de forma móvel, em qualquer lugar onde o profissional esteja, com o auxílio de tecnologias; ou no ambiente residencial, em home-office (COSTA, 2004). 
O home-office tem demonstrado ser a prática mais consolidada de teletrabalho no Brasil. Segundo dados do IBGE, aproximadamente $23 \%$ dos brasileiros ocupados no Brasil, trabalham no mesmo local onde residem, o que representa cerca de 20 milhões de pessoas (IBGE, 2010). A pesquisa, porém, não levanta dados sobre o tipo de trabalho ou de contratação, atendo-se somente ao local de trabalho, não sendo possível deduzir que esses indivíduos sejam adeptos ao teletrabalho. A pesquisa Home Office Brasil (SOBRATT, 2016), conduzida pela empresa SAP Consultoria com o apoio institucional da SOBRATT (Sociedade Brasileira de Teletrabalho e Teleatividades), levantou dados sobre o teletrabalho a partir do estudo de 325 empresas, no período de outubro de 2015 a março de 2016. Entre as empresas levantadas, $68 \%$ já apresentavam a prática do teletrabalho em diversas modalidades, e $37 \%$ adotavam o teletrabalho em home-office. É importante ressaltar, porém, que das empresas levantadas que adotavam o teletrabalho, apenas $61 \%$ tinham a prática formalizada ou em processo de formalização. Entre as empresas estudadas, $93 \%$ eram empresas privadas e $7 \%$ empresas públicas. Apesar da pequena porcentagem de empresas públicas participantes na pesquisa mencionada, percebe-se uma expansão do teletrabalho na administração pública brasileira, especialmente no Poder Judiciário, que conta com regulamentação da prática pelo CNJ - Conselho Nacional de Justiça, através da Resolução 227/2016. Após quase um ano da regulamentação do teletrabalho pelo Poder Judiciário, estima-se que, até junho de 2017, quase 2\% dos servidores da esfera trabalhista já haviam aderido à modalidade (CNJ, 2017).

Discute-se muito a respeito das vantagens do teletrabalho, seja no nível social, como: melhora no fluxo de trânsito, diminuição da poluição e do número de acidentes, inclusão de minorias no mercado de trabalho, revitalização econômica de regiões afastadas dos grandes centros de produção; ou no nível organizacional, como: corte de despesas com a estrutura física, redução do absenteísmo, produtividade do trabalhador, etc. (COSTA, 2004). Costa (2004) aponta também as possíveis vantagens para o trabalhador, como a possibilidade de equilíbrio entre família e trabalho, economia de tempo e de gastos com deslocamentos, flexibilidade de horários, entre outras. Embora apresente vantagens, o teletrabalho vem despertado preocupações em diversas áreas de conhecimento, em especial em relação a ergonomia e fatores humanos. Entre essas novas preocupações destacam-se a quantidade de horas trabalhadas, que pode ser muito maior do que nos escritórios físicos, o isolamento social, a desatualização profissional, as interferências do ambiente familiar no trabalho e a adequação ergonômica da área de trabalho. Tais preocupações são agravadas pela falta de legislação específica sobre o teletrabalho no Brasil.

A Lei 13.467 (BRASIL, 2017), que altera o texto da Consolidação das Leis do Trabalho - CLT (BRASIL, 1943) e entrou em vigor em outubro de 2017, incluiu disposições específicas a respeito do teletrabalho. A partir dessa mesma lei, o teletrabalho passou a figurar entre as atividades que não estão sujeitas ao controle de jornada e, por consequência, a verbas de natureza trabalhista como horas-extras ou adicionais, o que pode acarretar um aumento da carga de trabalho. Em relação à adaptação do posto de trabalho, a CLT indica que disposições relativas à aquisição de equipamentos e infraestrutura necessária ao trabalho serão previstas em contrato de trabalho escrito, não trazendo recomendações a este respeito. A CLT não detalha requisitos ergonômicos, mencionando apenas a obrigação que o empregador tem de instruir os empregados quanto a precauções que devam ser tomadas a fim de evitar doenças e acidentes de trabalho, devendo o empregado assinar termo de responsabilidade comprometendo-se a segui-las.

\section{Método}

De modo a levantar diretrizes a serem consideradas na adequação do ambiente residencial 
ao teletrabalho, foi realizada uma pesquisa bibliográfica. Inicialmente, buscaram-se normas brasileiras que regulamentam a ergonomia em postos de trabalho de escritório, sendo analisados também artigos científicos que indicam recomendações para o teletrabalho em home-office. A pesquisa voltou-se a aspectos da ergonomia física, incluindo a ergonomia do ambiente construído, elencando também algumas características da ergonomia organizacional que são relevantes para o estudo do teletrabalho. As diretrizes encontradas nessas publicações foram filtradas e adaptadas para a situação do teletrabalho, sendo apresentadas e, posteriormente, sintetizadas em uma imagem informativa.

\section{Diretrizes Ergonômicas para o Teletrabalho em Home-Office}

\subsection{Características do Posto de Trabalho}

A Norma Regulamentadora 17 (MTE, 2007), que dispõe sobre ergonomia, indica alguns requisitos para o mobiliário do posto de trabalho em geral. Ao se transferir o posto de trabalho para o ambiente residencial, considera-se que tais requisitos também devam ser verificados, adequandose o ambiente residencial a eles. Os requisitos são os seguintes: altura da superfície de trabalho compatível com a altura do assento, o tipo de atividade e a distância dos olhos ao campo de trabalho; área de trabalho de fácil alcance e visualização; dimensões que possibilitem o posicionamento e movimentação dos segmentos corporais. Em relação aos assentos, a NR 17 (MTE, 2007) indica que eles deverão ter altura ajustável; apresentar pouca ou nenhuma conformação da base do assento; encosto com leve curvatura para proteção da região lombar e borda frontal arredondada. A norma indica também que o assento deve dispor de apoio de braços regulável em altura de 20 a $25 \mathrm{~cm}$ a partir do assento, porém que o seu comprimento não deve interferir na acomodação da cadeira em relação à mesa. Essa recomendação é direcionada aos trabalhadores de teleatendimento, podendo, porém, ser transposta para a situação dos teletrabalhadores. Caso os pés do trabalhador não encostem no chão, é necessário também um apoio que permita esse ajuste. De acordo com a norma, deve-se evitar movimentação frequente do pescoço ou fadiga visual, posicionando a tela do computador, no caso dos trabalhadores estudados, de forma que facilite a sua visualização, ou seja, na altura dos olhos do trabalhador. A tela do computador deve também evitar reflexos e ofuscamentos, oferecendo condições de mobilidade que permitam o seu ajuste de acordo com a iluminação do ambiente. Indica-se, de acordo com a NR 17 (MTE, 2007), que o teclado seja independente e que tenha mobilidade, permitindo o seu ajuste e devendo estar no mesmo plano do mouse, estando o monitor em um plano acima, com o seu topo aproximadamente no nível dos olhos. Uma recomendação importante é a utilização de cadeira com rodízios que permita a mobilidade do trabalhador e sua acomodação sob a superfície de trabalho. O mobiliário deve ter cantos arredondados e não apresentar superfícies reflexivas ou especulares, também para evitar o ofuscamento, consequência da iluminação que será vista a seguir. A Figura 1 ilustra as recomendações previstas na NR 17, indicando também informações como a distância recomendada entre os olhos do trabalhador e a tela do computador, e os ângulos adequados de articulações de braços e pernas. 


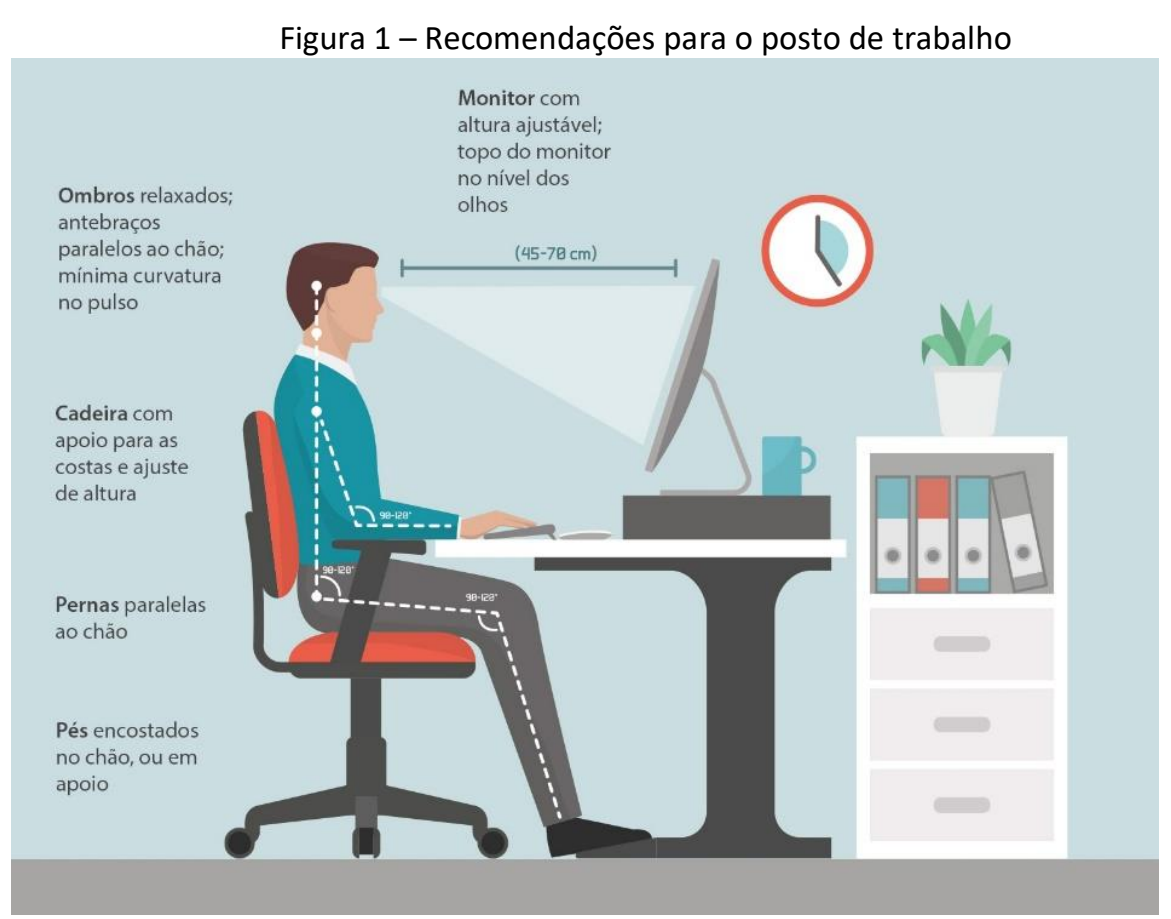

Fonte: adaptado de ergotribe.com/laptop-ergonomics/ (2018)

Como é usual que os teletrabalhadores trabalhem com computadores portáteis ou laptops, sejam eles próprios ou fornecidos pela organização, é importante que se adeque esse tipo de equipamento às recomendações, como na Figura 2. Neste caso, pode ser feita a elevação ou inclinação do equipamento de modo a posicionar a tela na altura indicada, utilizando-se teclado e mouse independentes, que deverão estar em um plano abaixo do plano da tela, na altura dos antebraços.

Figura 2 - Adequação de computadores portáteis
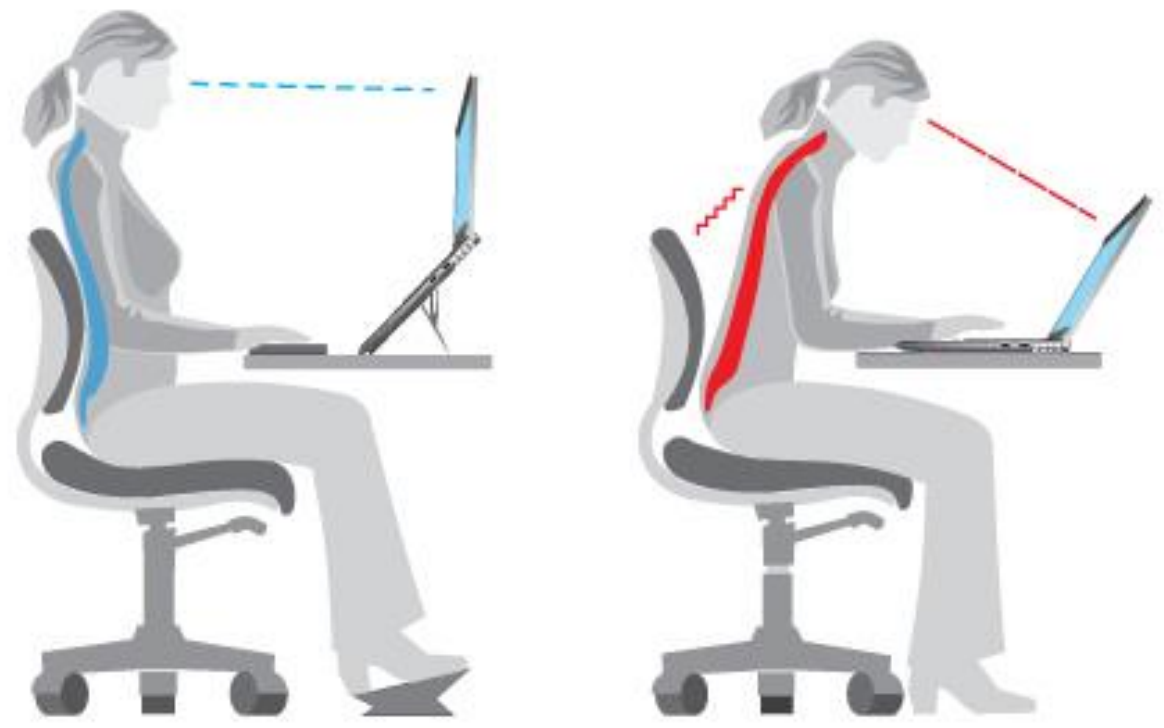

Fonte: posturemedic.co.uk/computers/ (2018) 


\subsection{Características do Ambiente de Trabalho}

Para que o ambiente residencial seja adequado à realização das atividades de trabalho, é necessário considerar alguns fatores importantes, como o ruído, a temperatura e a iluminação. $O$ ambiente de trabalho deve oferecer nível de ruído de até 65 decibels (dB), de acordo com a NBR 10152 (ABNT, 2017). A temperatura deve ser controlada, variando entre $20^{\circ} \mathrm{C}$ e $23^{\circ} \mathrm{C}(\mathrm{MTE}, 2007)$. A NBR ISO 8995-1 (ABNT, 2013) identifica a importância da iluminação em relação a três fatores principais: o conforto visual, o desempenho visual e a segurança visual. Em relação ao nível de iluminação a mesma norma determina o valor de iluminância média de 500 lux para estações de projeto assistido por computador, o que se aplica à modalidade estudada, indicando um índice de reprodução de cor de 80 . O índice de reprodução de cor (IRC) é um dado proveniente da fonte de luz, e deve ser fornecido pelo fabricante das lâmpadas. Uma consequência importante a ser evitada, no que concerne à iluminação, é o ofuscamento. O ofuscamento é a sensação produzida por áreas brilhantes ou pontos de iluminação excessiva no campo de visão, e pode ser de forma direta, estando o trabalhador em frente a uma janela, por exemplo, ou indireta, através da reflexão de superfícies especulares. No ambiente residencial, o nível de iluminância pode ser favorecido pela iluminação natural, através da proximidade de janelas. Porém, para que sejam evitados ofuscamentos e reflexos, é desejável que a mesa de trabalho esteja próxima à janela de forma lateral, devendo o controle da luz natural ser realizado através de anteparos como persianas ou "brises" (ABNT, 2013).

Entre as principais consequências relatadas do teletrabalho, tem-se as interferências do ambiente residencial e da família no trabalho. De forma a contornar essas interferências e possíveis conflitos, é desejável que o ambiente de trabalho seja delimitado, separado do ambiente residencial. Essa separação pode ser feita de forma física e estrutural, destinando-se um cômodo apenas para o trabalho, ou de forma artificial e mesmo simbólica, através da ambientação ou de vestuários que se assemelhem aos adotados na organização. Além de evitar interferências ou conflitos entre família ou ambiente residencial e o teletrabalho, esse tipo de artifício é utilizado pelos trabalhadores para facilitar a sua autogestão (NOHARA et al., 2010).

\subsection{Características Organizacionais}

O excesso de horas trabalhadas é uma consequência comum do teletrabalho em relação às modalidades de trabalho convencionais, verificada tanto no Brasil (COSTA, 2004; BOONEN, 2002; ROSENFIELD; ALVES, 2011) como em outros países (KELLIHER; ANDERSON, 2010; WHEATLEY, 2012). A inclusão do teletrabalho no rol de atividades que não estão sujeitas ao controle de jornada, conforme apontado anteriormente, aumenta a preocupação em relação às horas trabalhadas, ou mesmo à extensão das jornadas. Como o teletrabalhador frequentemente é quem gerencia seus próprios horários e tempo de trabalho, é importante que esteja atento às horas de trabalho desempenhadas, realizando pausas frequentes. Pode-se, para este fim, acatar a recomendação da NR 17 (MTE, 2007) para trabalhadores de teleatendimento em atividades de entrada de dados, devido à semelhança nas atividades, de que sejam realizadas pausas de 10 minutos a cada 50 minutos trabalhados.

A flexibilidade e a autonomia são frequentemente consideradas como vantagens do teletrabalho. Rosenfield e Alves (2011), porém, consideram o teletrabalho uma modalidade mais flexível do que autônoma, colocando a questão da autonomia como um paradoxo: ao mesmo tempo que o trabalhador tem autonomia para gerir o próprio tempo, não tem controle sobre ele, pois o 
tempo de trabalho é determinado pelo volume e pelos prazos. Alguns autores relatam, inclusive, uma possível diminuição dos prazos e intensificação do trabalho, como consequência do poder das tecnologias de informação e comunicação de acelerarem as tarefas (ALVES; 2009; ROSENFIELD, ALVES, 2011). Destaca-se, a partir dessas considerações, a importância da organização do trabalho e das tarefas para evitar consequências negativas, relacionadas à mudança do trabalho para o ambiente residencial, para o teletrabalhador. Devido à distância característica da modalidade de teletrabalho, a comunicação também desempenha papel fundamental, como indicado por Hertel, Geister e Konradt (2005), que destacam também outros pontos importantes para o gerenciamento de equipes virtuais ou dispersas, como: metas e funções claras; suporte contínuo com feedback e informações sobre cada trabalhador; criação de experiências de interdependência entre a equipe e treinamentos. Bentley et al. (2016) examinaram o papel do suporte organizacional em consequências do teletrabalho, especificamente a tensão psicológica ou stress, a satisfação profissional e o isolamento social. Os estudos dos autores demonstraram a relação direta do suporte organizacional com essas medidas, resultando no aumento de satisfação profissional e na atenuação do stress e do isolamento social, uma das consequências mais verificadas no teletrabalho. O suporte organizacional deve contemplar características pessoais, técnicas e organizacionais, devendo as recomendações a respeito da adaptação do ambiente residencial ao trabalho partir da organização. Há casos em que a organização fornece equipamentos ou auxílio financeiro para a adaptação do espaço, porém é importante que sejam realizados treinamentos e acompanhamentos periódicos dos teletrabalhadores em home-office, como discutido por Harrington e Walkers (2004). Os autores compararam um grupo de teste e um grupo de controle, sendo o grupo de teste submetido a um treinamento de ergonomia para home-office. Através do estudo, os autores puderam verificar que $44 \%$ dos participantes do estudo indicaram ter experenciado desconfortos ou dores durante o teletrabalho, sendo a incidência maior entre aqueles que desempenham o teletrabalho com maior frequência, ou seja, mais vezes por semana. $O$ estudo indicou a importância do treinamento de ergonomia para os teletrabalhadores, salientando que $85 \%$ deles nunca haviam recebido tal treinamento. Foi relatado também um aumento do conhecimento dos trabalhadores do grupo de teste, que completou o treinamento de ergonomia, além de mudanças posteriores em seus home-offices, com base no treinamento recebido.

\section{Síntese das Diretrizes Ergonômicas para o Teletrabalho em Home-Office}

Com o objetivo de apresentar e sintetizar as diretrizes compiladas no presente estudo, foi gerada uma imagem esquemática (Figura 3 ) que as subdivide, de forma ilustrativa, entre os domínios apresentados, a saber: características do posto de trabalho; características do ambiente de trabalho e características organizacionais. 


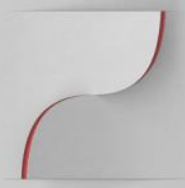

Figura 3 - Diretrizes Ergonômicas para o Teletrabalho em Home-Office

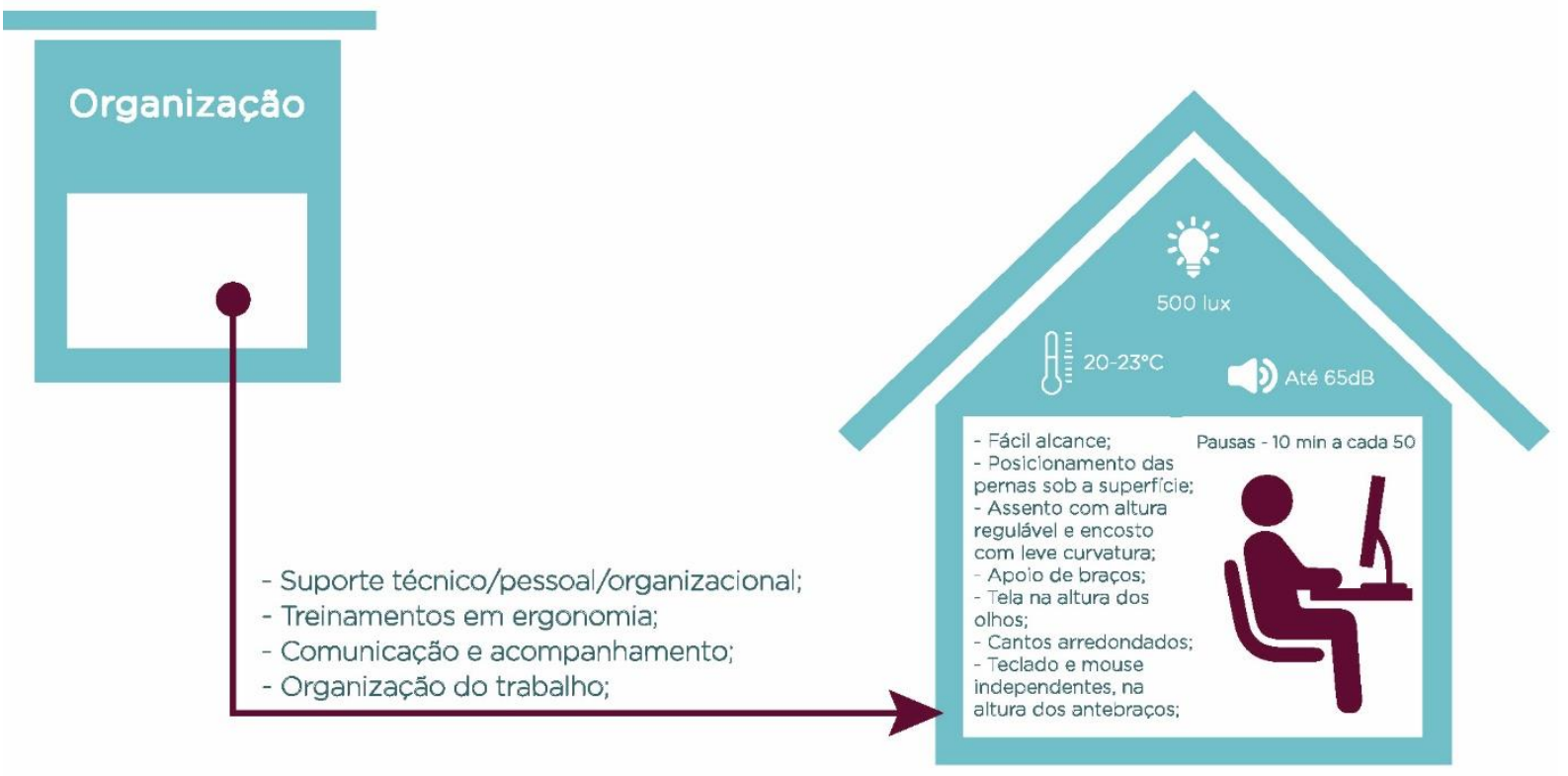

Fonte: os autores

\section{Conclusão}

O presente estudo buscou analisar as diretrizes e recomendações provenientes de leis, normas e artigos científicos, acerca da ergonomia no ambiente de trabalho, direcionando-as para o estudo do teletrabalho em home-office. A pesquisa demonstrou uma escassez de publicações científicas sobre recomendações ergonômicas no trabalho residencial, ainda que tenha se mostrado uma demanda, já que essa modalidade de trabalho conta com especificidades que devem ser tratadas isoladamente. Percebeu-se também, entre as publicações que abordam as consequências do teletrabalho para o trabalhador, pouca aderência com questões organizacionais, demonstrando uma escassez de publicações que realizem uma análise integrada, englobando os subsistemas sociotécnicos. Através do levantamento das diretrizes existentes, principalmente a partir de normas destinadas ao trabalho em escritórios, pôde-se ter um panorama dessas e da sua aplicação no teletrabalho em home-office. Percebeu-se também que, apesar de as normas utilizadas serem as mesmas destinadas ao trabalho em escritórios tradicionais, é necessário transpor essas normas ao ambiente residencial e à realidade do teletrabalho. Em estudos futuros, tem-se a necessidade de divulgação das diretrizes para teletrabalho em home-office a profissionais e organizações que desejem implementá-lo ou estudá-lo. Também poderão ser realizadas pesquisas empíricas que atestem, a partir das diretrizes apresentadas, a forma como a ergonomia vem sendo conduzida nos programas de teletrabalho, e as consequências disso para os trabalhadores e organizações.

\section{Agradecimentos}

Os autores agradecem à Coordenação de Aperfeiçoamento de Pessoal de Nível Superior (CAPES) e ao Programa de Pós-Graduação em Design da UDESC pelo apoio na realização desta pesquisa. 


\section{Referências}

ABERGO. $O$ que é ergonomia. Disponível em: <http://www.abergo.org.br/internas.php?pg=o_que_e_ergonomia>. Acesso em: 18 mar. 2018.

ALVES, D. A. de. Tecnologias como mediadores das mudanças sociotécnicas no teletrabalho. TOMO, v. 15, p. 143-165, 2009.

ASSOCIAÇÃO BRASILEIRA DE NORMAS TÉCNICAS. NBR 10152: Acústica - Níveis de pressão sonora em ambientes internos a edificações. Rio de Janeiro, 2017.

ASSOCIAÇÃO BRASILEIRA DE NORMAS TÉCNICAS. NBR ISO/CIE 8995-1: Iluminação de ambientes de trabalho. Rio de Janeiro: Abnt, 2013.

BENTLEY, T. A. A.; TEO, S. T. T. T. T.; MCLEOD, L.; TAN, F.; BOSUA, R.; GLOET, M. The role of organisational support in teleworker wellbeing: A socio-technical systems approach. Applied Ergonomics, v. 52, p. 207-215, jan. 2016.

BOONEN, E. M. As várias faces do teletrabalho. E \& G Economia e Gestão, v. 2/3, n. 4/5, p. 106127, 2002.

BRASIL. Decreto-lei no 5.452, de 1943. Consolidação das Leis do Trabalho. Rio de Janeiro, maio. 1943.

BRASIL. Lei no 13.467, de 13 de julho de 2017. Altera a Consolidação das Leis do Trabalho (CLT), aprovada pelo decreto-lei no 5.452 , de 10 de maio de 1943 , e as leis nos 6.019 , de 3 de janeiro de 1974, 8.036, de 11 de maio de 1990, e 8.212, de 24 de julho de 1991, a fim de adequar a legislação às novas relações de trabalho. Brasília, 2017.

CNJ. Normatizado há um ano, teletrabalho agrada tribunais e servidores. Disponível em: <http://www.cnj.jus.br/noticias/cnj/84854-normatizado-ha-um-ano-teletrabalho-agrada-

tribunais-e-servidores>. Acesso em: 09 set. 2017.

COSTA, Isabel de Sá Affonso da. Poder/saber e subjetividade na construção do sentido do teletrabalho. 2004. 124 f. Tese (Doutorado) - Administração, Escola Brasileira de Administração Pública e de Empresas, Fundação Getulio Vargas, Rio de Janeiro, 2004.

GRANDJEAN, Etienne. Manual de Ergonomia: Adaptando o trabalho ao homem. 4. ed. Porto Alegre: Bookman, 1998.

HARRINGTON, S. S.; WALKERS, B. L. The effects of ergonomics training on the knowledge, attitudes, and practices of teleworkers. Journal of Safety Research, v. 35, n. 1, p. 13-22, 2004.

HENDRICK, H.W.; KLEINER, B.M. Macroergonomics: Theory, Methods, and Applications. Lawrence Erlbaum Associates, New Jersey (2002).

HERTEL, G.; GEISTER, S.; KONRADT, U. Managing virtual teams: A review of current empirical research. Human Resource Management Review, v. 15, n. 1, p. 69-95, 2005.

ILO - International Labour Office. Challenges and opportunities of teleworking for workers and employers in the ICTS and financial services sectors: Issues paper for the Global Dialogue Forum on the Challenges and Opportunities of Teleworking for Workers and Employers in the ICTS and Financial Services Sectors. Geneva: International Labour Office, 2016.

KARWOWSKI, Waldemar. The Discipline of Human Factors and Ergonomics. In: SALVENDY, Gavriel 
(Ed.). Handbook of Human Factors and Ergonomics. 4. ed. Hoboken: John Wiley \&amp; Sons, Inc., 2012. p. 3-37.

KELLIHER, C.; ANDERSON, D. Doing more with less? flexible working practices and the intensification of work. Human Relations, v. 63, n. 1, p. 83-106, 2010.

MINISTÉRIO DO TRABALHO E EMPREGO. NR 17: Ergonomia. Brasília, 2007.

NOHARA, J. J.; ACEVEDO, C. R.; RIBEIRO, A. F.; SILVA, M. M. da. O Teletrabalho na Perceção dos Teletrabalhadores. RAI - Revista de Administração e Inovação, v. 7, n. 2, p. 150-170, 2010

ROSENFIELD, C. L.; ALVES, D. A. Autonomia e trabalho informacional: 0 teletrabalho. Dados Revista de Ciências Sociais, v. 54, n. 1, p. 207-233, 2011.

SOBRATT. Pesquisa HOME OFFICE BRASIL 2016: Teletrabalho e Home Office, uma tendência nas empresas brasileiras. 2016. Disponível em: <http://www.sobratt.org.br/index.php/11-e-12052016estudo-home-office-brasil-apresenta-o-cenario-atual-da-pratica-no-pais-sap-consultoria/>. Acesso em: 07 nov. 2017.

WHEATLEY, D. Good to be home? Time-use and satisfaction levels among home-based teleworkers. New Technology, Work and Employment, v. 27, n. 3, 2012. 